\title{
Effect of Addition Cobalt Nanoparticles on Sn-Ag-Cu Lead-free Solder
}

\author{
S.L.Tay, A.S.M.A. Haseeb and Mohd Rafie Johan \\ Department of Mechanical Engineering, University of Malaya, \\ 50603 Kuala Lumpur, Malaysia \\ E-mail: haseeb@um.edu.my
}

\begin{abstract}
Nowadays, nanoelectroctronic, electro-nanotechnologies environmental friendly products become the roadmap in industry. Hence, nanoscale of reinforcement into lead-free solder becomes more popular rather than the micro size of reinforcement. In this paper, Cobalt nanoparticles-reinforced $\mathrm{Sn}-\mathrm{Ag}-\mathrm{Cu}$ composite solders were prepared by thoroughly blending $0.75 \mathrm{wt} \%$ of cobalt nanoparticles with near eutectic cement tended to suppress the growth of $\mathrm{Cu}_{3} \mathrm{Sn}$ intermetallic layer. However, upon addition of Co nanoparticles, the growth of $\mathrm{Cu}_{6} \mathrm{Sn}_{5}$ was enhanced. The distribution of the Co nanoparticles was observed by the elemental mapping which was carried out by using electron micro probe analysis (EPMA) and transmission electron microscopy which equipped together with electron-dispersive X-ray spectroscopy (TEM-EDX). There was no Co detected in the $\mathrm{Cu}_{3} \mathrm{Sn}$, it only presented in $\mathrm{Cu}_{6} \mathrm{Sn}_{5}$. The interdiffusion coefficient was increased with the ageing temperature. Upon additionof Co nanoparticles, the interdiffusion coefficient for the formation of $\mathrm{Cu}_{3} \mathrm{Sn}$ intermetallic layer was reduced, but the interdiffusion coefficient for the formation of $\mathrm{Cu}_{6} \mathrm{Sn}_{5}$ layer was increased. The activation energy for the formation of $\mathrm{Cu}_{3} \mathrm{Sn}$ was also increased with the Co addition.
\end{abstract}

Keywords: Lead-free solder, intermetallic layer, nanoparticles, cobalt nanoparticles

\section{Introduction}

Solder materials play an important role in electronic packaging for interconnection and as a surface coating for component leads and PCB surface finishes. In recent years, the usage of $\mathrm{Pb}$, which can be harmful to the human body, has attracted much global attention. Due to the environmental concern, it has prompted intense research activities on leadfree solder.

Among the numerous lead-free solder options, $\mathrm{SnAgCu}$ (SAC) is the most prevailing alloy family for electronic soldering. [1] However, the properties of $\mathrm{Sn}-\mathrm{Ag}-\mathrm{Cu}$ alloys are not adequate enough to meet severe board level reliability requirements. [2] To improve the properties of the lead-free solder, various elements were suggested added into common lead-free solder either by alloying or reinforcing particles.

Co has been attracting a great deal for recent of its benefit such as improve the ductility [3], reduce the brittle failure mode in BGA solder joint [4], improve thermal fatigue, creep resistance [5] and etc. As the development of nano technology has become active lately, various nano-sized particles were
SAC387 solder paste. Soldered samples were then subjected to high temperature ageing at 125,150 and $175^{\circ} \mathrm{C}$ for up to 1008 hours. In the solder joint, $\mathrm{Cu}_{6} \mathrm{Sn}_{5}$ intermetallic was observed on $\mathrm{Cu}$ substrate, followed by $\mathrm{Cu}_{3} \mathrm{Sn}$ intermetallic formation between $\mathrm{Cu}_{6} \mathrm{Sn}_{5}$ and $\mathrm{Cu}$ after prolonged ageing. The thickness of both IMC increased with the ageing time and ageing temperature. The Co nanoparticle reinfor chosen as reinforcements in producing composite lead-free solders. The nano-sized particles were added in the hope that they could possible more effective compared to the micronsized reinforcements. [6]

Research effort the effect of nanoparticle reinforced composite is in an early stage. Study of the Co nanoparticles addition is even scarce. Amagai [7] studied the effect of addition Co nanoparticles into $\mathrm{Sn}-3.5 \mathrm{Ag}$ solder after multiple reflow cycles on the interfacial structure and drop performance. However, the performance of solder joint at high temperature and the kinetic analysis is important to determine the reliability joint. In this paper focuses on the effect of Co nanoparticle additions to $\mathrm{Sn}-3.8 \mathrm{Ag}-0.7 \mathrm{Cu}$ solder paste on the interfacial reaction between the nanocomposite solder and $\mathrm{Cu}$ substrate during high temperature ageing. The activation energy of the diffusion for each IMC growth is also determined.

\section{Experimental Procedures}

Nanocomposite solder (Sn-3.8Ag-0.7Cu+0.75 n-Co) was prepared by mixing $\mathrm{Sn}-3.8 \mathrm{Ag}-0.7 \mathrm{Cu}$ (SAC) solder paste (Indium Corporation of America, Singapore) with commercial Co nanoparticles ( $28 \mathrm{~nm}$, Accument Materials, Co., USA). The solder paste was manually blended with Co nanoparticles approximately for 30 minutes. Solders were prepared on commercial polycrystalline copper sheets $(30 \mathrm{~mm}$ x $30 \mathrm{~mm}$ x $0.3 \mathrm{~mm}$ ). Prior to soldering, the sheets were cleaned and dipped in 50 vol\% $\mathrm{HNO}_{3}$ to remove oxide and then rinsed thoroughly in distilled water followed by cleaning with acetone. After the surface preparation the composite solder paste was placed on the copper substrate through a mask having an opening diameter of $6.5 \mathrm{~mm}$ and $1.24 \mathrm{~mm}$ thickness (JIS Z3198-3, 2003). Then the composite solder paste was reflowed on a hot plate at $250^{\circ} \mathrm{C}$ for $45 \mathrm{~s}$. After the reflow, the solder joint was cleaned to remove the flux residue. The reflowed samples were subjected to aging at 3 different temperatures at 125,150 and $175^{\circ} \mathrm{C}$ up to $1008 \mathrm{~h}$. After the aging tests, the samples were cross sectioned and polished to a $0.02 \mu \mathrm{m}$ finish employing the standard metallographic techniques. The microstructure was examined by an optical microscope and a scanning electron microscope (SEM). The 
average thickness of the IMCs was calculated by dividng the area of IMC by its length with the aided Olympus Analysis Five Software. The elemental analysis of the phases was carried out using energy-dispersive X-ray spectroscopy (EDX) and electron probe microanalysis (EPMA, JEOL-8500F). For a better resolution, selected samples were also investigated by using a Philips CM200 transmission electron microscope attached together with energy-dispersive X-ray spectroscopy (TEM-EDX). The TEM specimens were prepared by using XT Nova NanoLab 200 which was combining a dual beam high resolution focussed ion beam (Ga FIB) and a high resolution scanning electron microscope. The milled sample was liftout by using ex-situ liftout microscope and then put on the $\mathrm{Cu}$ grid. The activation energy for the formation of each IMCs was calcaluted via Arrhenius eauation.

\section{Results and Discussion}

Fig.1 shows the cross sectional micrographs of SAC and $\mathrm{SAC}+0.75 \mathrm{n}-\mathrm{Co}$ after reflow and ageing at $150{ }^{\circ} \mathrm{C}$ for $504 \mathrm{~h}$. A scallop shaped intermetallic layer (lighter layer) was formed in the SAC sample after reflow. Upon the addition of $\mathrm{Co}$ nanoparticles, the morphology of IMC changes substantially. The IMC layer appears to have a relative flat morphology with the addition of $\mathrm{Co}$ nanoparticles. After prolonged aging another intermetallic layer (darker layer) with a planer shape formed in between the first intermetallic layer and $\mathrm{Cu}$ substrate in the both SAC and nanocomposites. The morphology of inner darker layer is seen to be similar in both SAC and nanocomposites. The thickness of this dark IMC layer is thicker in the SAC samples compared with Co nanoparticles added SAC solder. Energy dispersive spectroscopy was used to determine the composition of each layer. By comparing the ratio of $\mathrm{Cu}: \mathrm{Sn}$, it is inferred that the outer layer is $\mathrm{Cu}_{6} \mathrm{Sn}_{5}$ and the inner layer is $\mathrm{Cu}_{3} \mathrm{Sn}$. Co was found in $\mathrm{Cu}_{6} \mathrm{Sn}_{5}$ IMC in the nanocomposite solder in the ratio of $(\mathrm{Cu}, \mathrm{Co})_{6} \mathrm{Sn}_{5}$. However, within the resolution of EDX, there was no Cobalt detected in $\mathrm{Cu}_{3} \mathrm{Sn}$.
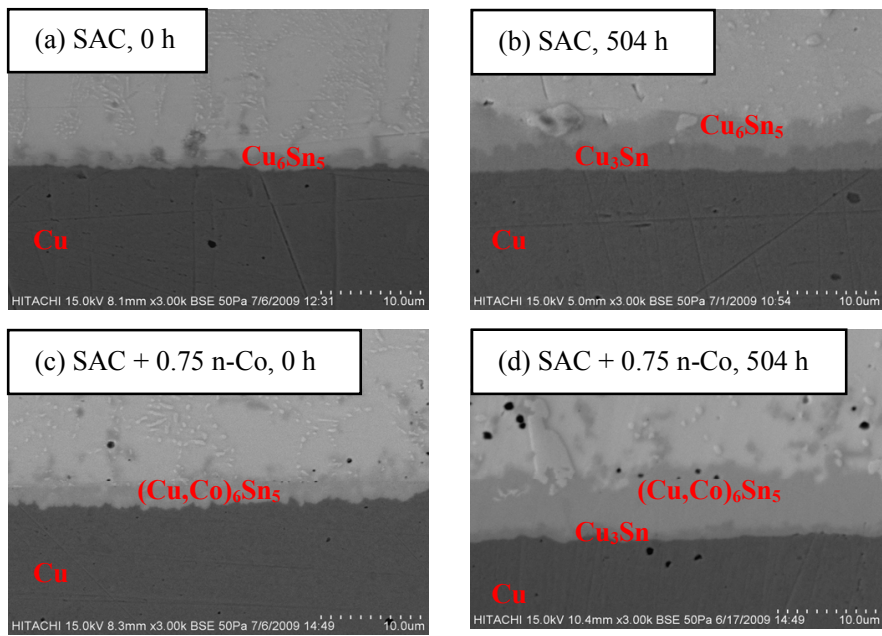

Fig. 1. SEM micrographs of solder-substrate interface after ageing at $150^{\circ} \mathrm{C}$ for $0 \mathrm{~h}$ and $504 \mathrm{~h}$.

Fig. 2 shows the elemental mapping of $\mathrm{SAC}+0.75 \mathrm{n}-\mathrm{Co}$ nanocomposite after as- reflowed by using electron probe microanalyser (EPMA) and transmission electron microscope which is equipped together with elemental dispersive spectrometer (TEM-EDX). Result show that the concentration of Co nanoparticles in the $(\mathrm{Cu}, \mathrm{Co})_{6} \mathrm{Sn}_{5}$ layer was higher on the top IMC layer compared to the bottom IMC layer. This result is similar with other researchers who found out the outer region of $\mathrm{Cu}_{6} \mathrm{Sn}_{5}$ contained higher concentration of Co or $\mathrm{Ni}$ than the inner region for the $\mathrm{Sn}-3.5 \mathrm{Ag}$ solder alloy dope with Co or Ni as additives. $[8,9]$

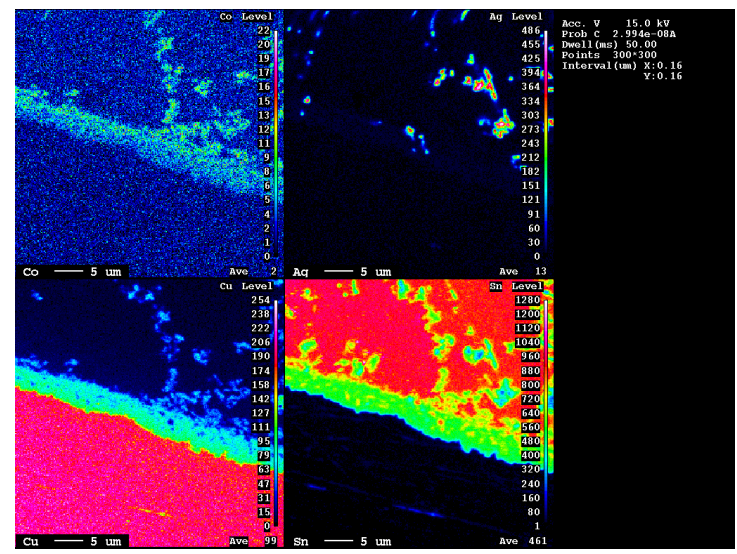

(a)
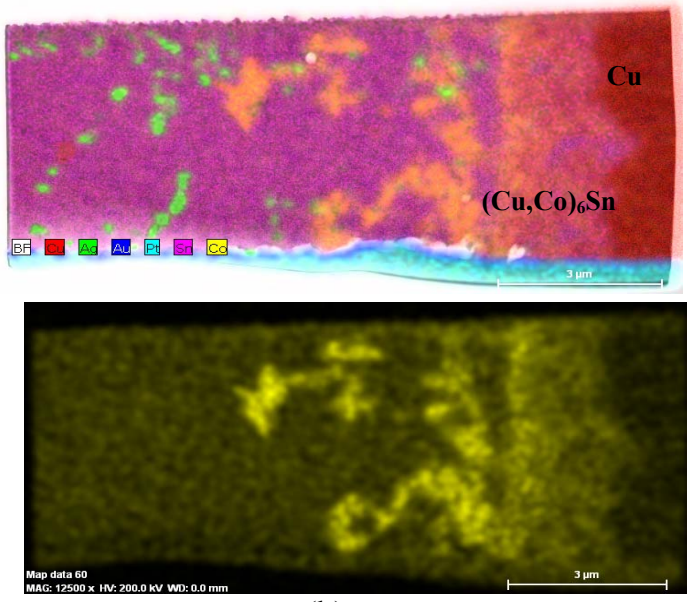

(b)

Fig. 2. Elemental mapping of $\mathrm{SAC}+0.75 \mathrm{n}-\mathrm{Co}$ nanocomposite after as- reflowed by using (a) EPMA, (b) TEM-EDX.

Table 1 shows the interdiffusion coefficient of total, $\mathrm{Cu}_{6} \mathrm{Sn}_{5}$ and $\mathrm{Cu}_{3} \mathrm{Sn}$ intermetallic layer for the $\mathrm{SAC}$ solder and $\mathrm{SAC}$ doped with Co nanoparticles. It is assumed that the diffusion controlled is the main growth mechanism for the intermetallic formation. The interdiffusion coefficient $\left(D_{\text {eff }}\right)$ of the each IMC layer can be determined by the following equation (1):

$$
x_{t}-x_{0}=\left(D_{e f f}\right)^{1 / 2}
$$

where $x_{t}$ is the thickness of IMCs at time $t, x_{0}$ is the thickness after reflow, $D_{\text {eff }}$ is the interdiffusion coefficient in the IMC layer. For the $\mathrm{Cu}_{3} \mathrm{Sn}$ layer, $x_{0} \approx 0$, due to only a few tens $\mathrm{nm}$ can form after reflow and it is usually not resolvable under an SEM. [10,11]

$201012^{\text {th }}$ Electronics Packaging Technology Conference 
The interdiffusion coefficient is tended to increase with the temperatures for all the IMC layers. Upon addition of $\mathrm{Co}$ nanoparticles, the interdiffusion coefficient for $\mathrm{Cu}_{3} \mathrm{Sn}$ is much smaller in the (SAC+0.75 n-Co) composite compare to SAC solder. The addition of Co nanoparticles therefore has a significant influence on the growth kinetics of $\mathrm{Cu}_{3} \mathrm{Sn}$. On the other hand, the interdiffusion coefficient for the growth of $\mathrm{Cu}_{6} \mathrm{Sn}_{5}$ is tended to decrease. This finding might be related to the IMC thickness. The IMC of $\mathrm{Cu}_{6} \mathrm{Sn}_{5}$ is enhanced but the IMC of $\mathrm{Cu}_{3} \mathrm{Sn}$ is suppressed with the presence of $\mathrm{Co}$. With the higher IMC thickness, the interdiffusion coefficient also increases. Gao et. al. [12] studied the studied the effect of Co as an alloying addition to $\mathrm{Sn}-3.5 \mathrm{Ag}$. The thickness of $\mathrm{Cu}_{6} \mathrm{Sn}_{5}$ and the total IMC thickness were found to be higher for Co alloyed solder at all aging time. The growth of $\mathrm{Cu}_{3} \mathrm{Sn}$, however, was suppressed by Co alloy addition. It has been observed that during IMC formation, $\mathrm{Co}$ atoms enter the $\mathrm{Cu}$ sublattice of $\mathrm{Cu}_{6} \mathrm{Sn}_{5}$ and substitutes some of the $\mathrm{Cu}$ atoms. [13] Theoretical calculation revealed that the presence of Co in the IMC causes a greater reduction in the heat of formation and hence makes $\mathrm{Cu}_{6} \mathrm{Sn}_{5}$ more stable. Furthermore, the driving force for the diffusion of $\mathrm{Sn}$ through $(\mathrm{Cu}, \mathrm{Co})_{6} \mathrm{Sn}_{5}$ increases in Co nanoparticle added solder resulting in its faster growth. [14]

Table 1. Effective interdiffusion coefficient of each IMC layers at the interface.

\begin{tabular}{ccccc}
\hline \multirow{2}{*}{ Solder } & \multirow{2}{*}{ IMC } & \multicolumn{3}{c}{$\begin{array}{c}\text { Effective Interdiffusion Coefficient, } \\
\left(\mathbf{m}^{\mathbf{2}} \mathbf{s}^{-\mathbf{1}}\right)\end{array}$} \\
\cline { 3 - 5 } & & $\mathbf{1 2 5}^{\mathbf{0}} \mathbf{C}$ & $\mathbf{1 5 0}^{\mathbf{0}} \mathbf{C}$ & $\mathbf{1 7 5}^{\mathbf{0}} \mathbf{C}$ \\
\hline & Total & $5.38 \times 10^{-18}$ & $8.48 \times 10^{-18}$ & $3.68 \times 10^{-17}$ \\
SAC & $\mathbf{C u}_{\mathbf{6}} \mathbf{S n}_{\mathbf{5}}$ & $1.40 \times 10^{-18}$ & $2.35 \times 10^{-18}$ & $8.01 \times 10^{-18}$ \\
& $\mathbf{C u}_{\mathbf{3}} \mathbf{S n}$ & $5.35 \times 10^{-19}$ & $2.98 \times 10^{-18}$ & $1.01 \times 10^{-17}$ \\
\hline $\begin{array}{c}\text { SAC+ } \\
\mathbf{0 . 7 5}\end{array}$ & $\mathbf{T o t a l}_{\mathbf{n}-\mathbf{C o}}$ & $2.24 \times 10^{-18}$ & $8.81 \times 10^{-17}$ & $6.73 \times 10^{-17}$ \\
& $\mathbf{C u}_{\mathbf{6}} \mathbf{S n}$ & $1.19 \times 10^{-18}$ & $5.93 \times 10^{-18}$ & $4.14 \times 10^{-17}$ \\
\hline
\end{tabular}

The activation of energies for the diffusion of each IMC layer maybe calculated via the Arrhenius relation:

$$
D_{e f f}=D_{o} e^{(-Q / R T)}
$$

and can written as

$$
\ln D_{e f f}=\frac{-Q}{R T}+\ln Q_{o}
$$

where $D_{\text {eff }}$ is the interdiffusion coefficient, $D_{o}$ is the interdiffusion constant, $Q$ is the activation energy, $R$ is the ideal gas constant $(8.314 \mathrm{~J} / \mathrm{mol})$ and $\mathrm{T}$ is the absolute temperature. The activation energy for the layer growth was obtained from the slope of $\ln D$ (where $D$ is $D_{\text {eff }}$ ) versus $1 / \mathrm{T}$ plot multiplied by the ideal gas constant as shown in Fig. 3.
Results show that the activation energy for $\mathrm{Cu}_{3} \mathrm{Sn}$ is higher compared to the activation energy for the formation of total IMC or $\mathrm{Cu}_{6} \mathrm{Sn}_{5}$ in both $\mathrm{SAC}$ and $\mathrm{SAC}+0.75 \mathrm{n}-\mathrm{Co}$ composite solder. This result is similar with other researchers. [15-17] Upon addition Co nanoparticles, the activation energy for the formation of $\mathrm{Cu}_{3} \mathrm{Sn}$ increases. However, this finding was contrats to Vianco et al. (2004) [18] who found that the activation energy for $\mathrm{Cu}_{3} \mathrm{Sn}(38 \mathrm{KJ} / \mathrm{mol})$ was much lower than the total IMC $(58 \mathrm{KJ} / \mathrm{mol})$ for the $\mathrm{Sn}-0.5 \mathrm{Ag}-4.0 \mathrm{Cu}$ solder. It was also reported that the activation energy for both $\mathrm{Cu}_{3} \mathrm{Sn}$ and total IMC was similar $(50 \mathrm{KJ} / \mathrm{mol})$ for the $\mathrm{Sn}-3.9 \mathrm{Ag}$ $0.6 \mathrm{Cu}$ solder.

Due to the higher activation energy needed for the formation of $\mathrm{Cu}_{3} \mathrm{Sn}$, the layer of $\mathrm{Cu}_{3} \mathrm{Sn}$ might be retarded. The higher activation energy could reduce the atomic diffusion rate and thus inhibit the excessive of IMC. [19].

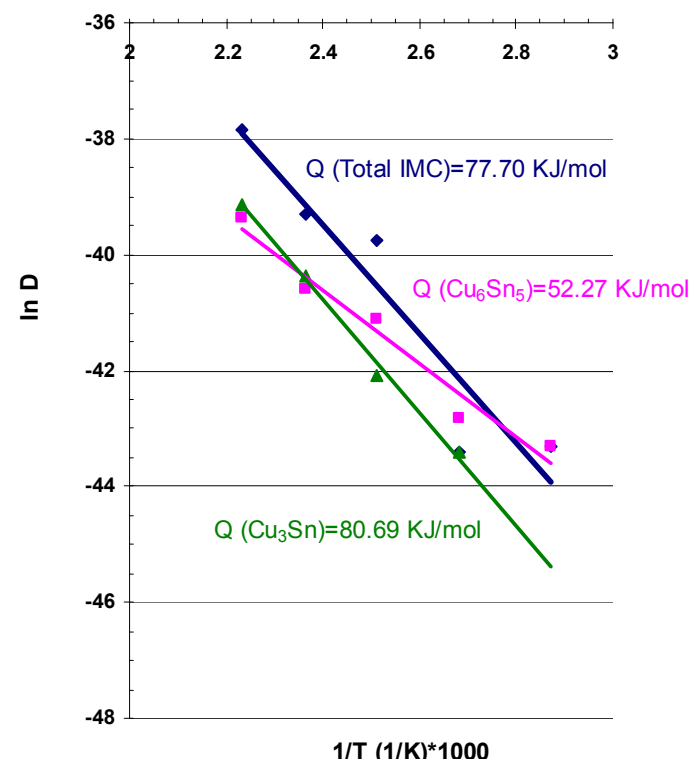

(a)

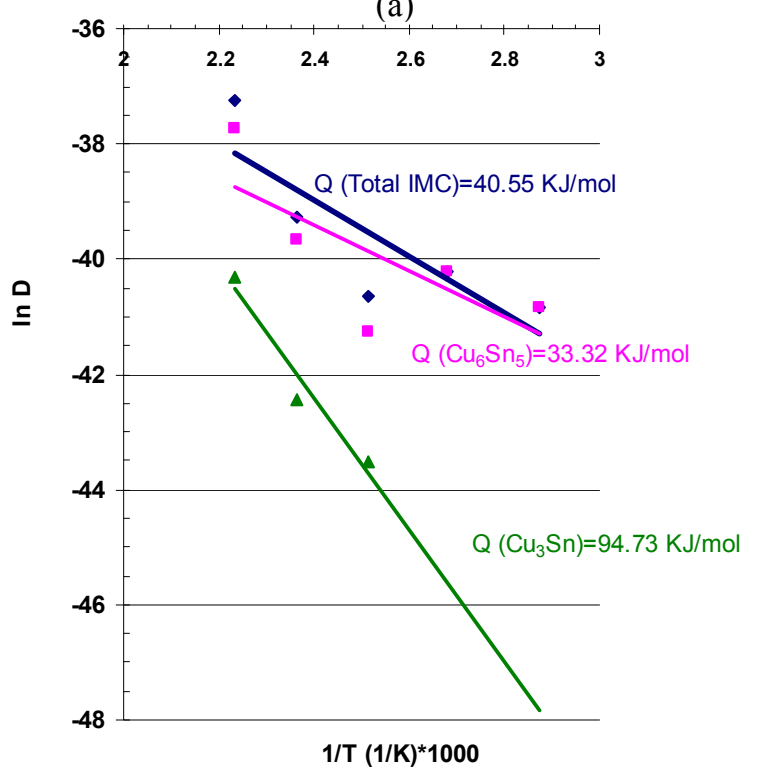

(b)

Fig. 3. Arrhenius plot of the IMC growth for (a) SAC387; (b) SAC387+0.75 n-Co solder joint.

$201012^{\text {th }}$ Electronics Packaging Technology Conference 


\section{Conclusions}

$\mathrm{Cu}_{6} \mathrm{Sn}_{5}$ is the first intermetallic layer formed in the interaction between solder and copper substrate. Upon the aging, another $\mathrm{Cu}$ rich intermetallic layer, $\mathrm{Cu}_{3} \mathrm{Sn}$ is formed in between the $\mathrm{Cu}_{6} \mathrm{Sn}_{5}$ intermetallic layer and $\mathrm{Cu}$ substrate. The thicknesses of both intermetallic layers are increasing with aging time and aging temperatures. The morphology on $\mathrm{Cu}_{6} \mathrm{Sn}_{5}$ after reflow changes from a scallop to a planner type upon addition of $\mathrm{Co}$ nanoparticles. $\mathrm{Co}$ is only present in the $\mathrm{Cu}_{6} \mathrm{Sn}_{5}$ intermetallic layer and there is no cobalt detected in $\mathrm{Cu}_{3} \mathrm{Sn}$. Co has higher concentration on the top region in $\mathrm{Cu}_{6} \mathrm{Sn}_{5}$ compare to the bottom region.

Upon addition of Co nanoparticles, the $\mathrm{Cu}_{3} \mathrm{Sn}$ is tended to be suppressed. The interdiffusion coefficient for the growth of $\mathrm{Cu}_{3} \mathrm{Sn}$ is also reduced with the addition of Co nanoparticles. The interdiffusion coefficients are increasing with the increasing of ageing temperature. The activation for the formation of the $\mathrm{Cu}_{3} \mathrm{Sn}$ is higher compared to the activation for the formation of total and $\mathrm{Cu}_{6} \mathrm{Sn}_{5}$ IMCs in both $\mathrm{SAC}$ solder and SAC-doped with Co nanoparticles.

\section{Acknowledgments}

The authors acknowledge the finance support from Mobility Fund, University of Malaya (211318) for the opportunity to run the research at Electron Microscopy Unit, University of New South Wales. Special thanks to Prof. Paul Munroe, Dr. Md. Zakaria Quadir, Dr. Charlie Kong, Mr. Sean Lim, Madam Katie Levick for their assistance with EPMA and TEM analysis.

\section{References}

1. Lee, N. C., Lead-free Soldering. In Daniel, L. and Wong, C. P. (eds.), Materials for Advanced Packaging, Springer Science Business Media (New York, 2009), pp. 181-218.

2. Amagai, M., "A study of nanoparticles in SnAg-based lead free solders," Microelectron. Reliab., Vol. 48, No. 1 (2008), pp. 1-16.

3. Anderson, I. E. and Harringa, J. L., "Suppression of void coalescence in thermal aging of tin-silver-copper-X solder joints," J. Electron. Mater., Vol. 35, No. 1 (2006), pp. 94-106.

4. Eu, P. L., Min, D., Wong, T. L., Amin, N., Ahmad, I., Lee, M. Y., et al., "A study of SnAgNiCo vs $\mathrm{Sn} 3.8 \mathrm{Ag} 0.7 \mathrm{Cu} \mathrm{C} 5$ lead free solder alloy on mechanical strength of BGA solder joint," Proc $10^{\text {th }}$ Electronic Packaging Technology Conf, Singapore, Dec. 2008, pp. 588-594.

5. Cheng, F. J., Nishikawa, H. and Takemoto, T., "Estimation of the thermal fatigue resistance and creep properties of the $\mathrm{Co} / \mathrm{Ni}$-bearing SAC305 lead-free solders by the strain rate change tensile test," Mater. Trans., Vol. 49, No.7 (2008), pp.1503-1507.

6. Guo, F., "Composite-lead free electronic solders," $J$. Mater. Sci.-Mater. Electron. Vol. 18, No. 1-3 (2007), 129-145.

7. Amagai, M.. "A study of nanoparticles in SnAg-based lead free solders," Microelectron. Reliab., Vol. 48, No.1 (2008), pp. 1-16.
8. Tsai, J. Y., Hu, Y. C., Tsai, C. M. and Kao, C. R., "A study on the reaction between $\mathrm{Cu}$ and $\mathrm{Sn} 3.5 \mathrm{Ag}$ solder doped with small amount of Ni," J. Electron. Mater., Vol. 32, No. 11 (2003), pp.1203-1208.

9. Gao, F., Nishikawa, H. and Takemoto, T., "Phase stability assessment and microstructure modification at lead-free solder joint," Proc $7^{\text {th }}$ Inter Conf on Electronic Packaging Technology, Shanghai, China, Aug. 2006, pp.1-6.

10. Gong, J. C., Liu, C. Q. and Silberschmidt, V. V., "Initial formation of $\mathrm{CuSn}$ intermetallic compounds between molten $\mathrm{SnAgCu}$ solder and $\mathrm{Cu}$ substrate," Scr. Mater., Vol. 60, No. 5 (2009), pp. 333-335.

11. Shang, P. J., Liu, Z. Q., Pang, X. Y., Li, D. X. and Shang, J. K., "Growth mechanisms of $\mathrm{Cu}_{3} \mathrm{Sn}$ on polycrystalline and single crystalline $\mathrm{Cu}$ substrates," Acta Mater., Vol. 57, No. 16 (2009), pp. 4697-4706.

12. Gao, F. and Takemoto, T., "The correlation between the intermetallic compounds growth pattern and the addition in the solder matrix," Proc $7^{\text {th }}$ Inter Conf on Thermal, Mechanical and Multiphtsics Stimulation and Experiments in Micro-Electronics and Microsytems, Como, Apr. 2006, pp.1-7.

13. Gao, F., Takemoto, T. and Nishikawa, H., "Morphology and growth pattern transition of intermetallic compounds between $\mathrm{Cu}$ and $\mathrm{Sn}-3.5 \mathrm{Ag}$ containing a small amount of additives," J. Electron. Mater. Vol. 35, No. 12 (2006), pp. 2081-2087.

14. Laurila, T., Hurtig, J., Vuorinen, V. and Kivilathi, J. K., "Effect of $\mathrm{Ag}, \mathrm{Fe}, \mathrm{Au}$ and $\mathrm{Ni}$ on the growth kinetics of $\mathrm{Sn}-\mathrm{Cu}$ intermetallic compound layers," Microelectron. Reliab. Vol. 49, No. 3 (2009), pp. 242-247.

15. Lee, C. B., Yoon, J. W., Suh, S. J., Jung, S. B., Yang, C. W., Shur, C. C., et al., "Intermetallic compound layer formation between $\mathrm{Sn}-3.5$ mass $\% \mathrm{Ag}$ BGA solder ball and $(\mathrm{Cu}$, immersion $\mathrm{Au} /$ electroless Ni-P/Cu) substrate," $J$. Mater. Sci. -Mater. Electron. Vol. 14, No. 8 (2003), pp. 487-493.

16. Watanabe, H., Hidaka, N., Shohji, I. and Ito, M., "Effect of $\mathrm{Ni}$ and $\mathrm{Ag}$ on interfacial reaction and microstructure of Sn-Ag-Cu-Ni-Ge lead-free solder," Mater. Sci. Technol. Vol. 1 (2006), pp. 135-146.

17. Yoon, J. W., Noh, B. I., Kim, B. K., Shur, C. C. and Jung, S. B., "Wettability and interfacial reactions of Sn-Ag$\mathrm{Cu} / \mathrm{Cu}$ and $\mathrm{Sn}-\mathrm{Ag}-\mathrm{Ni} / \mathrm{Cu}$ solder joints," J. Alloy. Compd. Vol. 486, No. 1-2 (2009),pp. 142-147.

18. Vianco, P. T., Rejent, J. A. and Hilava, P. F., "Solid-state intermetallic compound layer growth between copper and 95.5Sn-3.9Ag-0.6Cu solder," J. Electron. Mater., No. 33, No. 9 (2004), pp. 991-1004.

19. Li, G. Y. and Shi, X. Q., "Effects of bismuth on growth of intermetallic compounds in $\mathrm{Sn}-\mathrm{Ag}-\mathrm{Cu} \mathrm{Pb}$-free solder joints," Trans. Nonferrous Met. Soc. China, No. 16, No. 2 (2006), pp. s739-s743. 